\title{
Histiocitosis de células de Langerhans que semeja rectocolitis ulcerativa en un adulto: informe de un caso
}

\section{Adult-onset systemic Langerhans cells histocytosis mimicking ulcerative rectocolitis: a case report}

\author{
Lorena Estrada, José Marrero*, Libia Jiménez, Valentina Morante y Ana M. Sáenz \\ Servicio de Dermatología, Hospital Universitario de Caracas, Universidad Central de Venezuela, Distrito Capital, Venezuela
}

\begin{abstract}
Resumen
La histiocitosis de células de Langerhans $(H C L)$ es una entidad poco frecuente en adultos. Debido a la diversidad clínica de presentación y el escaso conocimiento de la entidad, la sospecha clínica es baja. Se presenta el caso de un paciente masculino de 26 años de edad, con pápulas y placas eritemato-descamativas en áreas seborreicas de la cara y el tórax anterior de siete años de evolución; se diagnostica y trata como dermatitis seborreica con mejoría parcial. Con posterioridad se añaden úlceras en pliegues inguinales, axilares e interglúteos y episodios de diarrea y estreñimiento. Se lo refiere al Hospital Universitario de Caracas con diagnóstico preliminar de pénfigo y es ingresado en regulares condiciones generales. Se toma biopsia de piel del borde de la úlcera y la valora el servicio de gastroenterología, que diagnostica rectocolitis ulcerativa relacionada con trombocitopenia, anemia e hipoalbuminemia. Con el estudio histológico se confirma el diagnóstico de HCL. Se inicia tratamiento con quimioterapia pero el paciente fallece a los pocos días. Esta afección de tan baja incidencia (1/1,000,000), subdiagnosticada en la mayor parte de los casos, representa sin duda alguna un reto diagnóstico.
\end{abstract}

Palabras clave: Colitis. Histiocitosis de células de Langerhans. Úlceras cutáneas.

\begin{abstract}
Langerhans Cell Histiocytosis ( $\mathrm{LCH}$ ) is a infrequent entity in adults. Due to its clinical variability, diagnose is delayed. We present a 26 years-old-male with a 7- years history of an erythematous scaly papules and plaques eruption in seborrheic area son his face and thorax, being diagnosed and treated as seborrheic dermatitis, getting a partial improvement of his symptoms. Later, he started developing ulcers in groin, axillary and gluteal folds and diarrhea with constipation. Through a skin biopsy, he is diagnosed with pemphigus vulgaris, receiving treatment without any improvement. He was referred to University Hospital of Caracas where he was evaluated by gastroenterology, diagnosed as ulcerative rectocolitis, associated with thrombocytopenia, anemia and hypoalbuminemia. Langerhans cells histiocytosis is diagnosed through skin biopsy. Treatment with chemotherapy is started but patient died within a few days after. This pathology of such low incidence $(1 / 1,000,000)$ represents, without a doubt, a diagnostic challenge.
\end{abstract}

Key words: Colitis. Langerhans cells histiocytosis. Skin ulcers.

Correspondencia:

*José Marrero

E-mail: joseamarrerov@gmail.com
Disponible en internet: 06-10-2021

Fecha de recepción: 29-05-2020

Fecha de aceptación: 13-08-2020

DOI: 10.24875/MCUT.20000039
Med Cutan Iber Lat Am. 2021;49(Suppl 1):21-25

www.MedicinaCutanealLA.com 0210-5187/C 2020 Colegio Ibero Latinoamericano de Dermatología A.C. (CILAD). Publicado por Permanyer. Este es un artículo open access bajo la licencia CC BY-NC-ND (http://creativecommons.org/licenses/by-nc-nd/4.0/). 


\section{Introducción}

Las histiocitosis se deben a la acumulación anómala de células del sistema mononuclear fagocítico (monocitos, macrófagos, células dendríticas). En la reclasificación de las enfermedades histiocíticas, la histiocitosis de células de Langerhans ( $\mathrm{HCL}$ ) pertenece al grupo I dentro de las cinco categorías. Ésta es el resultado de la proliferación clonal de las células de Langerhans $(C L)^{1}$. Se trata de una anomalía poco frecuente, cuya etiología y fisiopatología no se comprenden del todo. De acuerdo con su presentación, puede afectar a un solo órgano (monosistémica) al localizarse en un solo sitio (unifocal) o en sitios múltiples (multifocal). También puede comprometer a muchos órganos (multisistémica) con compromiso de un número limitado de órganos o con diseminación ${ }^{2}$. Se ha notificado una incidencia de 1 a 2 personas por 1,000,000 en adultos y se presenta con mayor frecuencia entre los dos y los 10 años de edad, con una proporción de complicaciones de $30 \%$ a $50 \%{ }^{3}$. Aunque la piel es el órgano afectado con más frecuencia, el compromiso gastrointestinal es extremadamente raro ( $1 \%-5 \%)$, puede causar diarrea, estreñimiento y hematoquecia y se considera de mal pronóstico. Se presenta un caso de HCL de inicio cutáneo y afectación gastrointestinal de curso crónico, recidivante y con desenlace letal.

\section{Caso clínico}

Paciente masculino de 26 años de edad, quien inicia su enfermedad durante los seis años anteriores a su ingreso, con pápulas eritematosas y placas eritemato-descamativas en áreas seborreicas de cara y tórax anterior. Recibe tratamiento para dermatitis seborreica, con mejoría parcial de los síntomas. Cuatro años más tarde se agregan úlceras en pliegues, episodios concomitantes de estreñimiento que alternan con diarreas, es valorado en diferentes centros asistenciales y recibe tratamientos diversos. Con estudio histológico diagnóstico de enfermedad ampollar (pénfigo vulgar) ingresa en el Hospital Universitario de Caracas para valoración y conducta. La exploración física identifica regulares condiciones generales; en la piel se observan placas eritemato-descamativas con tendencia a confluir, con descamación furfurácea y costras melicéricas en áreas seborreicas de cara (Fig. 1). Se observan úlceras en ambos pliegues axilares, inguinales e interglúteos, caracterizadas por bordes en declive, fondo hemorrágico con secreción amarillenta y eritema perilesional (Figs. 2 y 3). El resto de la exploración física es normal.

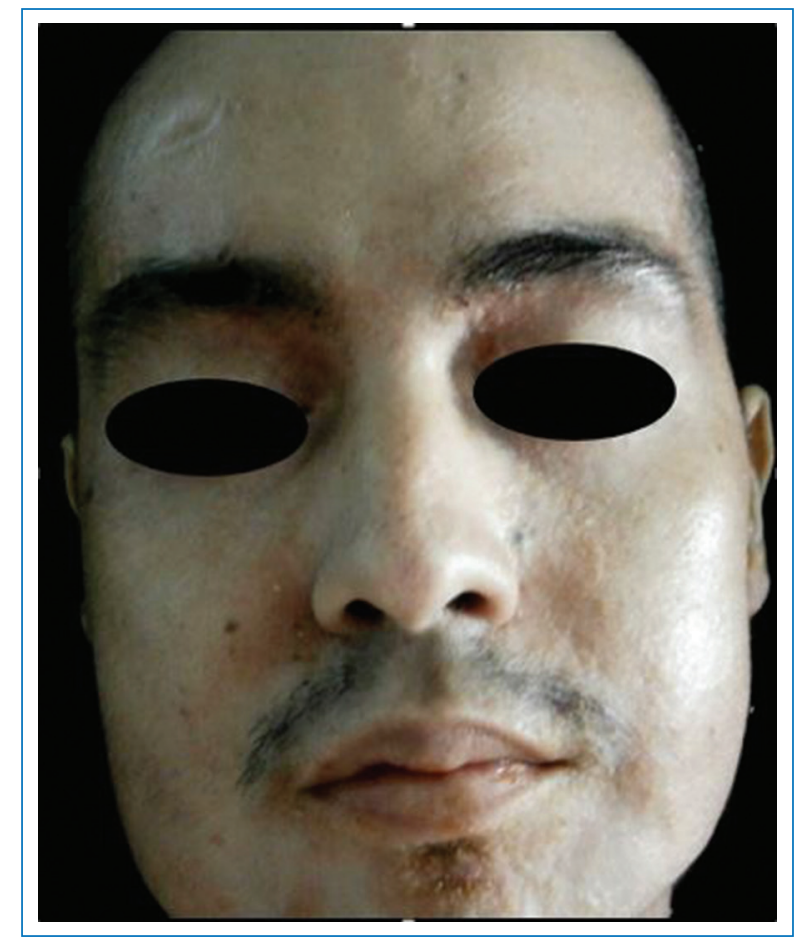

Figura 1. Placas eritemato-descamativas con tendencia a confluir, con descamación furfurácea y costras melicéricas en áreas seborreicas de cara.

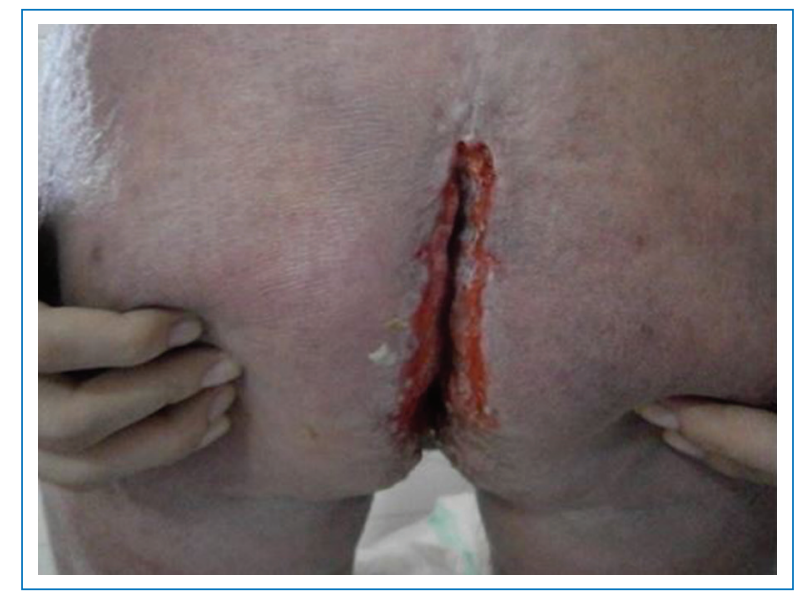

Figura 2. Se observan úlceras en ambos pliegues axilares, inguinales e interglúteos, caracterizadas por bordes en declive, fondo hemorrágico con secreción amarillenta y eritema perilesional.

En vista de los hallazgos, se plantean tres diagnósticos diferenciales: pénfigo, enfermedad de Crohn extraintestinal y rectocolitis ulcerativa. 


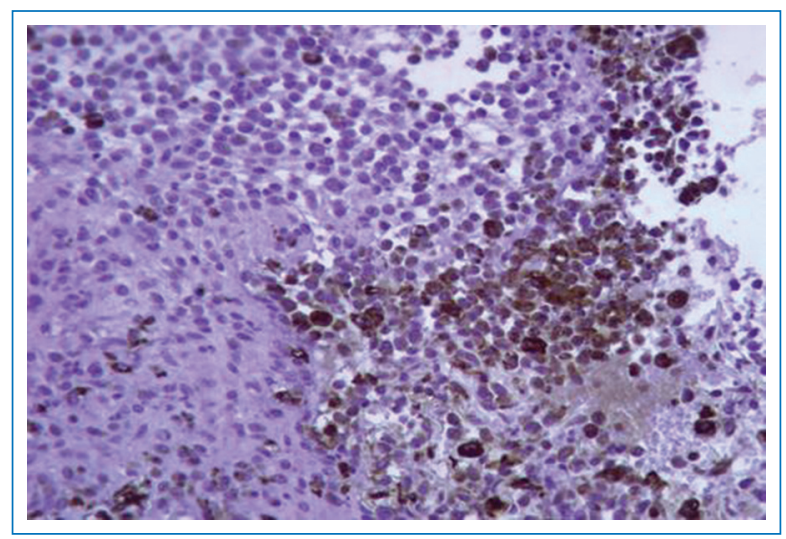

Figura 3. Histiocitosis de células de Langerhans.

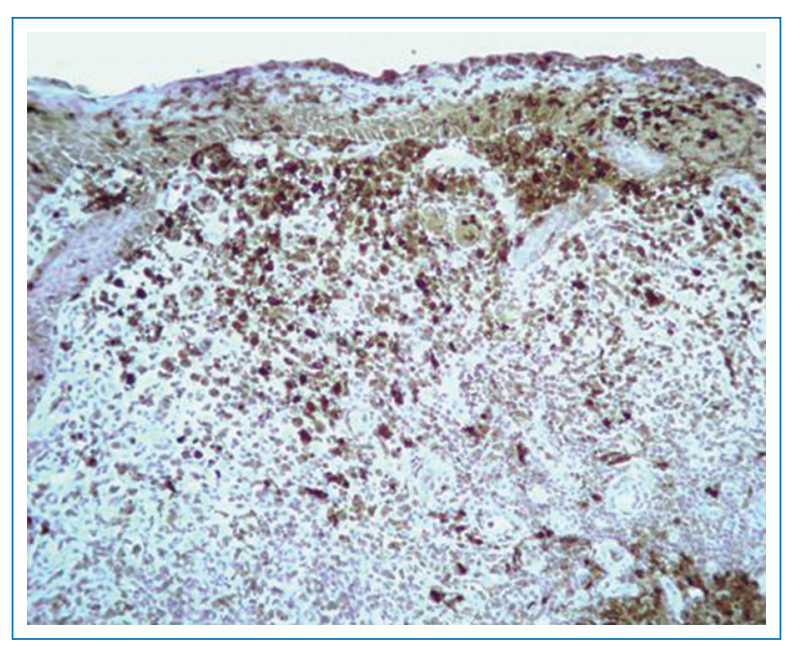

Figura 4. Infiltración difusa de la dermis por células redondas que comprometen la epidermis $(\mathrm{H}-\mathrm{E}, 4 \mathrm{x})$.

Se toma muestra de piel para estudio histológico y se observa infiltración difusa de la dermis por células redondas, las cuales comprometen la epidermis y en el aumento (40x) corresponden a células mononucleadas con hendiduras nucleares que confieren un aspecto en "grano de café". El diagnóstico de HCL (Figs. 4 y 5) se confirma con la inmunohistoquímica con tinción positiva para S100 (Fig. 6), CD68 y CD1a (Fig. 7) en células neoplásicas.

Durante su estancia hospitalaria se añaden al cuadro diarreico fiebre, distensión abdominal y petequias. Se valora en el servicio de gastroenterología, que plantea rectocolitis ulcerativa complicada con megacolon tóxico e indica realización de colonoscopia. Con posterioridad se observa un empeoramiento del estado general efecto de la anemia, hipoalbuminemia, desequilibrio



Figura 5. Células mononucleadas con hendiduras nucleares que dan un aspecto en "grano de café" (H-E, 40x).

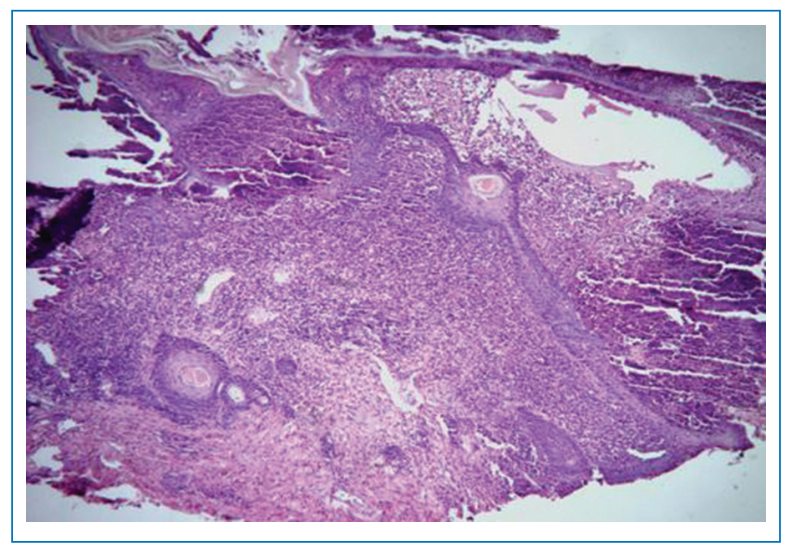

Figura 6. $S 100(10 x)$

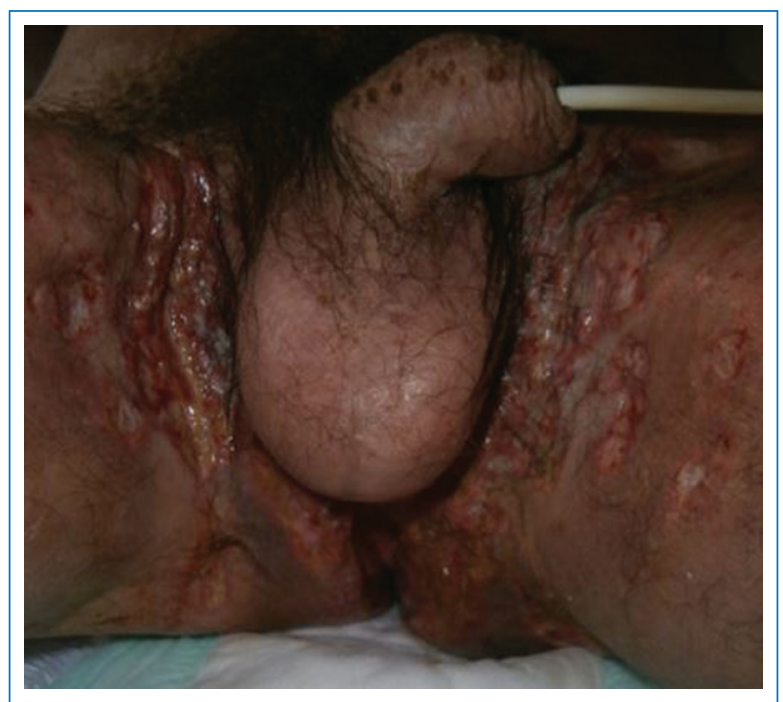

Figura 7. CD68 (20x). 
hidroelectrolítico y trombocitopenia, la cual empeora con rapidez. Se realiza ecografía abdominal que informa hepatoesplenomegalia.

El paciente inicia tratamiento con vinblastina, etopósido y metilprednisolona; sin embargo, la evolución es tórpida y fallece a los siete días.

\section{Discusión}

Como en el caso presentado, se trata de una entidad subdiagnosticada. Los pacientes muestran signos y síntomas de HCL durante muchos meses antes del diagnóstico definitivo y el tratamiento. En clínica, la HCL parece similar en los niños, aunque la incidencia en determinado órgano tal vez sea distinta. En adultos predomina la afectación pulmonar, monosistémica y relacionada con el tabaquismo. Otras diferencias con respecto a los niños son el compromiso genital y de la mucosa oral. Los síntomas de presentación varían de acuerdo con el órgano afectado. En este paciente, además de las lesiones cutáneas, se refieren diarrea y estreñimiento, lo que se vincula más adelante con fiebre y alteración del estado general ${ }^{4}$.

De los adultos con $\mathrm{HCL}$, el $37 \%$ tiene compromiso cutáneo como parte de la enfermedad multisistémica, ya que la afectación sólo en la piel es más común en los niños. Las lesiones cutáneas aparecen como exantema papular con áreas rojizas, pigmentadas o con costras de diversos diámetros. En el cuero cabelludo, el exantema es similar al de la dermatitis seborreica. En la región inguinal, los genitales o alrededor del ano se pueden presentar úlceras abiertas que no se curan después del tratamiento antibacteriano o antimicótico, características similares a las del caso presentado. En la boca, las encías suelen inflamarse o ulcerarse a lo largo de la mucosa yugal, encías y lengua ${ }^{1,2}$.

La frecuencia del compromiso óseo en adultos difiere de la de los niños. La mandíbula puede estar afectada hasta en el $30 \%$ de los casos y en $7 \%$ en los niños, mientras que el compromiso craneal es hasta de un $40 \%$ en niños, comparado con un $21 \%$ en adultos. El resto de los huesos comparte la misma frecuencia de presentación entre ambos grupos ${ }^{5}$.

Las manifestaciones gastrointestinales de la $\mathrm{HCL}$ ocupan un $5 \%$ del total de las presentaciones clínicas $^{6}$. En una serie de casos de HCL gastrointestinal se describió la frecuencia de las manifestaciones clínicas: un $86 \%$ de los pacientes muestra casi siempre exantema antes de las manifestaciones. Dentro de éstas, un $59 \%$ padece hematoquecia, $18 \%$ diarrea no sanguinolenta, $9 \%$ estreñimiento y en $4 \%$ de los pacientes se observan fístulas perianales. También se identifica hipoalbuminemia en un $17 \%$ de los casos, en relación con enteropatía perdedora de proteínas ${ }^{6}$. Con estas manifestaciones clínicas se plantean diagnósticos diferenciales, entre ellos la enfermedad inflamatoria intestinal (en particular la enfermedad de Crohn). El hallazgo del exantema maculopapular en áreas seborreicas es un signo de gran ayuda para diferenciar estas anomalías.

El diagnóstico debe establecerse a través de endoscopia y biopsia, bien sea de las lesiones cutáneas o de la mucosa afectada dentro del tracto gastrointestinal. En múltiples casos se ha diagnosticado la afección en el contexto de hallazgos fortuitos (como pólipos observados a través de una colonoscopia) en individuos asintomáticos. Sin embargo, lo más frecuente es hallar múltiples lesiones ulcerativas en focos del tracto gastrointestinal, y el colon y el duodeno son los órganos afectados con mayor frecuencia?.

Es importante resaltar la importancia de la biopsia cutánea en el diagnóstico de esta anomalía, en vista de que es un procedimiento menos invasivo que la biopsia de la mucosa gastrointestinal ${ }^{8}$. En el caso del paciente presentado, se efectuaron dos biopsias cutáneas, la última positiva para HCL. Sin embargo, el compromiso sistémico del paciente ya es bastante grave para lograr un tratamiento efectivo. A pesar de que es frecuente observar múltiples granulomas, rodeados de macrófagos, eosinófilos, células gigantes multinucleadas y linfocitos $T$, el diagnóstico final se determina al observar las células de Langerhans, caracterizadas por ser grandes, ovoides y mononucleares, con un núcleo que semeja la forma de un riñón o de un grano de café. También es importante identificar los gránulos de Birbeck dentro de estas células ${ }^{8}$.

El tratamiento sigue en esencia las pautas establecidas para el tratamiento de la HCL infantil, aunque no es claro si responden de manera similar. Se ha informado que los fármacos empleados tienen efectos secundarios que no toleran los adultos como los niños. El debate continúa en cuanto al tratamiento de primera línea. En este paciente, infortunadamente, el diagnóstico fue tardío.

Se ha descrito que el $60 \%$ de los pacientes diagnosticados de HCL fallece, el $50 \%$ durante los primeros 18 meses tras el diagnístico ${ }^{5}$. No existen informes en las publicaciones médicas sobre la incidencia de esta afección en Venezuela. 


\section{Conclusiones}

La HCL ha demostrado ser una anomalía de muy baja incidencia y mortalidad significativa, motivo por el cual todo médico debe conocer su epidemiología, principales presentaciones y tratamiento. De esta forma podrá tratarse de manera adecuada.

\section{Financiamiento}

No hubo financiamiento externo.

\section{Conflicto de intereses}

Los autores declaran no tener conflictos de intereses.

\section{Responsabilidades éticas}

Protección de personas y animales. Los autores declaran que para esta investigación no se han realizado experimentos en seres humanos ni en animales.

Confidencialidad de los datos. Los autores declaran que han seguido los protocolos de su centro de trabajo sobre la publicación de datos de pacientes.
Derecho a la privacidad y consentimiento informado. Los autores han obtenido el consentimiento informado de los pacientes y/o sujetos referidos en el artículo. Este documento obra en poder del autor de correspondencia.

\section{Bibliografía}

1. Emile JF, Abla O, Fraitaq S, Horne A, Haroche J, Donadieu J et al. Revised classification of histiocytosis and neoplasms of the macrophage-dendritic cell linages. Blood 2016;127:2672-81.

2. Naselof $C$, Basset $F$. From histiocytosis $X$ to Langerhans cell histiocytosis: a personal account. Int J Surg Pathol. 9(2):137-46.

3. Monsereenusorn C, Rodríguez-Galindo C. Clinical characteristics and treatment of Langerhans cell histiocytosis. Hematol Oncol Clin North Am. 2015;29:853-73.

4. Jezierska M, Stefanowicz J, Romanowicz G, Kosiak W, Lange M. Langerhans cell histiocytosis in children - a disease with many faces. Recent advances in pathogenesis, diagnostic examinations and treatment. Advances in Dermatology and Allergology/Postepy Dermatol Alergol. 2018:35(1):6-17.

5. Andión M, Ruano D, Azorín D, de Rojas T, Madero L. Histiocitosis de células de Langerhans con afectación gastrointestinal. Anales de Pediatría. 2015;83(4):227-294.

6. Hait E, Liang M, Degar B, Glickman J, Fox VL. Gastrointestinal tract involvement in Langerhans cell histiocytosis: case report and literature review. Pediatrics. 2006;118(5):e1593-9.

7. Singhi A Montgomery $E$ Gastrointestinal tract langerhans cell histiocytosis: a clinicopathologic study of 12 patients. Am J Surg Pathol. 2011;35(2):305-10.

8. Podjasek JO, Loftus CG, Smyrk TC, Wieland CN. Adult-onset systemic Langerhans cell histiocytosis mimicking inflammatory bowel disease: the value of skin biopsy and review of cases of Langerhans cell histiocytosis with cutaneous involvement seen at the Mayo Clinic. Int J Dermatol. 2014;53(3):305-11. 